\title{
The IMPACt of Web Site Campaigning on Traditional NeWS Media AND Public Information Processing
}

\author{
By Gyotae Ku, Lynda Lee Kaid, and Michael Pfau
}

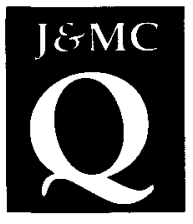

This study examined the impact of Web site campaigning on traditional news media agendas and on public opinion during the 2000 presidential election campaign. Based on an intermedia agenda-setting approach, this study demonstrated the direction of influence among three media in terms of the flow of information. An agenda-setting impact of Web site campaigning on the public was also identified.

The agenda of the news media has become a principal focus of attention in the agenda-setting process. ${ }^{1}$ The key question of "who sets the media's agenda?" has revived an interest in the flow of news stories and story ideas among the news media.

Since White's 1949 gatekeeping study, there have been concerns about how the issues in institutional media systems are prioritized. ${ }^{2}$ The greatest attention has been paid to the relationship among media. For example, based on this concept of an intermedia-agenda function, Roberts and $\mathrm{McCombs}^{3}$ found that the news agendas of different news organizations impact each other. However, inquiry into the intermediaagenda function has centered around traditional media, mainly newspapers and television. The current study also considers new media influence in the intermedia agenda-setting function.

Since the 1996 political campaign, the Internet has been examined as a means of political information exchange. ${ }^{4}$ To mobilize supporters, political candidates have begun to convey their voices "on the net." Today nearly all candidates have an online strategy. Most have established Websites where information on the candidate's background, issue statements, and supporters, as well as day-to-day campaign information, can be obtained. Internet networks can also influence public exposure to information, ${ }^{5}$ creating opportunities for individuals and groups to affiliate and participate in civic affairs and public life, and active involvement in political campaigns by Internet users has been reported. ${ }^{6}$ Given the growth of Internet campaigning and the role of the online information user as opinion leader, Internet campaigning should be considered an important channel of information.

JEMC Quarterly Vol. 80, No.3 Autumn 2003 528-547 (C2003 AEJMC
Gyotae $K u$ is lecturer at the Department of Communication, Keimyung University, South Korea. Lynda Lee Kaid is senior associate dean for graduate studies $\mathcal{E}$ research and professor, College of Journalism and Communications, University of Florida. Michael Pfau is professor and chair, Department of Communication, University of Oklahoma. 
Some attention has been paid to the content of Web sites and their implications in social and political life, ${ }^{7}$ but little attention has been given to how new technologies affect the flow of information in relation to other media channels. This intermedia agenda-setting study examines how political campaign Web sites shape or interact with the traditional news media's agenda.

Political Campaigns through the Internet. Despite divergent claims about the impact of Internet campaigning, the Internet has clearly been a part of a political phenomenon in which a great amount of political information is exchanged between politicians and the public. ${ }^{8}$ In particular, the Internet has become a valuable source supplementing traditional media such as newspapers and television in information dissemination and retrieval. ${ }^{9}$

The year 1996 might well be called "The Year of New Media Politics," in that political candidates began rushing to establish a presence "on the net." In the 1996 general elections, fifty of sixty-eight senatorial candidates had home pages. ${ }^{10}$ The 1996 presidential election was also the first national contest to show evidence of the power of the Internet as a mass medium. According to Meddis, ${ }^{11}$ Bob Dole's Web site recorded more than four-million "hits."

Scholars do not uniformly believe in the widespread efficacy of the Internet for political information. Not only do some citizens lack Internet access, but many do not actively seek out political information through Web sources. ${ }^{12}$ Nonetheless, candidates' political Web sites are also accessible news sources for the traditional media. According to Whillock, ${ }^{13}$ candidates in 1996 routinely sent press releases via their home pages and often directly to journalists' e-mail addresses in an effort to frame campaign issues to their advantage. Since most major newspapers and television stations are connected to the Internet, ${ }^{14}$ members of the traditional media can also visit an online campaign press gallery to pick up the daily briefing, the day's digital-quality video and audio clips, or candidate schedules.

Systematic examinations of the contents of political campaign Web sites have focused on simple observation ${ }^{15}$ and have been limited to the Internet itself as a medium. Little attention has been given to a dynamic relationship among media or the role of campaign Web sites in relation to traditional media.

Intermedia Agenda Setting across Media. Since McCombs and Shaw's seminal agenda-setting research, ${ }^{16}$ their assumptions have provided a theoretical basis for numerous and diverse political communication studies. Most of these agenda-setting studies have used a mix of media to identify issue agendas. A causal relationship between media coverage and the salience of topics in the minds of receivers has been generally accepted in agenda-setting studies. ${ }^{17}$ However, Lang and Lang note: "The whole question of how issues originate is sidestepped, nor is there any recognition of the process through which agendas are built or through which an object that has caught public attention, by being big news, gives rise to a political issue."18 
Other works have outlined distinct agenda-setting roles for different media channels. ${ }^{19}$ For example, Shaw and McCombs report that newspapers have a major agenda-setting role on political issues with TV playing a lesser role. ${ }^{20}$ Although their study focused on a relationship between specific media and the public, not among the media themselves, the findings could imply that each medium might be uniquely involved in the "agenda building" process.

Before a news agenda emerges, there may be some structural mechanisms involved in the news process. For example, television, according to Cronkite, ${ }^{21}$ frequently repeats a newspaper story. Nevertheless, agenda-setting researchers have verified an agenda-setting function without specifying the nature of the relationship among mass media agendas. That is, most agenda-setting research has widely accepted the media agenda as a given. ${ }^{22}$ There are only a few studies focusing on the process by which media contents are constructed. ${ }^{23}$

Research has found that newspapers tend to influence the broadcast agenda more than the reverse. ${ }^{24}$ In this view, the news media can be regarded as intermediary structures involved in news processing of other media. In addition, intermedia relationship studies have examined how campaign issues fluctuate across the media. Roberts and McCombs investigated the agenda-setting interrelationship among newspaper coverage, television coverage, and political advertising during the 1990 Texas gubernatorial campaign. ${ }^{25}$ Their study confirms political advertising as an agenda setter for both television news and newspaper coverage of the issues. Boyle's research on the 1996 presidential campaign, which looked at political spots, newspaper stories, and network news coverage, also found a significant impact of candidate television advertising on the agenda of newspaper and television news agendas, particularly for the opposing/challenging candidate, Bob Dole. ${ }^{26}$ This suggests that candidate-controlled messages, such as advertising, may be a strong factor in influencing media agendas and points to the importance of considering whether the candidate-controlled Web sites have a similarly strong relationship with the agendas of print and television news outlets.

\section{Research Questions}

Because presidential candidates are a primary focus in the daily flow of news ${ }^{27}$ and candidates' Web sites have been identified as important news sources for the traditional news media, ${ }^{28}$ this study investigated the extent to which the news agenda embodied in candidates' Web sites influences the subsequent agenda of campaign activities and issues covered by other news media.

RQ1: Do candidate Web sites exert an intermedia agenda-setting influence on traditional media?

Despite a close relationship among media in news processing; as Kaid and Sanders maintain, ${ }^{29}$ considerable debate exists over the question of which medium serves as the primary news source for the public. The present study examined how different media formulated the issue salience of 2000 presidential campaign news. 
RQ2: How do presidential candidates' Web sites influence the public's agenda?

A content analysis was conducted to determine 2000 campaign news agendas of newspaper, television, and candidate Web sites. Each medium's agenda was rank ordered and compared with other media agendas and polling data about the public's issue salience.

Sampling. The agenda of each medium was compiled from three seven-day time periods between 5 September and 7 November. This variation in time period for comparing campaign agendas among news media was designed to examine the manner in which the temporal variable influences agenda-setting processes among media or between media and the public. A random number table was used to choose the first day for analysis in each time period, but a deliberate attempt was made to ensure that the last two time periods fell during the last month of the campaign. Thus, each news sample comprised 7 consecutive days, excluding weekend days, resulting in the following time periods: Time 1 - 20 to 28 September, except 23 and 24; Time $2-12$ to 20 October, except 14,15 ; Time 3 - 27 October to 6 November, except 28, 29 October and 4, 5 November. Because some television networks do not air their evening news on the weekend, these two days were excluded.

The first research focus was on two prestigious national newspapers, the New York Times and the Washington Post, chosen because of their impact on public opinion and prior research establishing their importance in setting the media agenda for national issues. ${ }^{30}$ To collect newspaper articles related to the 2000 election campaign, The Lexis-Nexis Academic Universe was used with keywords "presidential campaign" or "election" with the candidates' names (Gore and Bush).

Evening newscasts from three networks (ABC, CBS, NBC) were analyzed to compute the campaign news agendas of TV. After locating stories in the Vanderbilt Television News Archive Abstracts, we analyzed videotaped copies of actual news stories. Despite the proliferation of cable news channels, the three network channels still represent a substantial audience in excess of cable channels and probably have a great impact on the public's information processing. ${ }^{31}$

For the candidates' Web site agendas, we examined the news release directory in the official Web sites that were established by the two presidential candidates, Al Gore and George W. Bush. The news releases at Time 1 and 2 were fully downloaded by identifying their unique http addresses (URL). Because of data availability issues after the election, the news releases at Time 3 were gathered through the Internet Archive (www.archive.org/collections/e2k.html). The "news release directory" containing news releases was the only daily-based news source on the candidates' Web sites operated by the two candidates, so it seemed to be the best source to ascertain the presidential candidates' agendas.

In addition, to see what impact news media coverage had on the public agenda, three public opinion polls corresponding to the three time periods chosen in this study were collected through "polls \& surveys" in The Lexis-Nexis Academic Universe. The first two surveys were conducted 
by CBS News and the New York Times during the following periods: respectively, 27 September to 1 October and 18 October to 21 October. CBS News conducted the last survey between 29 October and 31 October 2000. The question used to gauge the public's agenda in those telephone surveys was: "What do you think is the single most important problem for the government-that is, the President and Congress-to address in the coming year?"

Categories of the Media Agenda. To determine the campaign issue agendas of news media, we analyzed the news media contents, and reviewed the July 2000 Gallup poll results. ${ }^{32}$ The news agenda attention to political ads, TV shows, fundraisers, minorities, and world affairs issues was dismissed because of the small number of news stories, leaving an array of ten issues that could then be used to compare media, Web, and public agendas. The ten issues were public education, national economy, health care, Social Security, federal tax, handling budget, environment, national defense, energy policy, and crime.

Measurement. As in typical agenda-setting research, ${ }^{33}$ this study counted the air time (in seconds) of campaign news on television. Each televised campaign news story was considered as the unit for coding. The researcher and one graduate student coded the stories. Coders identified how coverage time within stories was distributed among the issue categories. On a sample of $20 \%$ of the newscasts, intercoder reliability checks produced a perfect score.

For newspaper and Web site news agendas, the Microsoft Word software program was used to count keywords related to the ten issues. ${ }^{30}$ According to Kaid and Wadsworth, ${ }^{31}$ examination of manifest content and quantification are crucial in content analysis. As in Roberts and McCombs's study," the program counted "the frequency of a specific issue word and/or related issue words." Each keyword was entered into the program's "Find" feature in "Edit" and manually counted. Words with fewer than five hits were excluded. As a validation technique, the researcher manually examined the program's results for accuracy and context.

Statistical Analysis. A rank ordering of the ten issues for the 2000 presidential campaign was compiled for each of the agendas examined, and then explored using cross-lagged correlations between points in time. To make cross-lagged comparisons, rank-order correlations (Spearman's rho) were used, and the Rozelle-Campbell baseline statistic was computed to determine the significance of the cross-lagged correlation coefficients in terms of directionality. ${ }^{33}$

In addition, partial correlation analyses were conducted to measure the strength of the association between two variables, controlling for other variable(s). The key benefit of such analysis, as Roberts and McCombs indicate, ${ }^{34}$ is in determining whether the second variable adds any predictive value.

Websites' Campaign Agenda. A total of 280 news stories were identified and analyzed in the two official candidates' Web sites (Gore139, Bush-141). Gore's Web site produced 6,524 hits related to the ten news agenda issues out of 109,737 words, while Bush's Web site had 
TABLE 1

Campaign News Agenda in Candidates' Web Sites

Web Sites

\section{Time 1}

F $\%$

Time 2

\%

Fime 3

\begin{tabular}{lrrrrrrrr}
\hline Health Care & 1,057 & $(29)$ & 754 & $(22)$ & 591 & $(21)$ & 2,402 & $(24)$ \\
Budget Handling & 649 & $(18)$ & 564 & $(16)$ & 503 & $(18)$ & 1,716 & $(17)$ \\
Social Security & 283 & $(8)$ & 596 & $(17)$ & 542 & $(19)$ & 1,421 & $(14)$ \\
Taxes & 305 & $(8)$ & 545 & $(16)$ & 341 & $(12)$ & 1,191 & $(12)$ \\
Education & 380 & $(10)$ & 261 & $(8)$ & 360 & $(13)$ & 1,001 & $(10)$ \\
Economy & 288 & $(8)$ & 236 & $(7)$ & 287 & $(10)$ & 811 & $(9)$ \\
Energy Policy & 439 & $(12)$ & 62 & $(2)$ & 37 & $(1)$ & 538 & $(5)$ \\
Crime & 82 & $(2)$ & 282 & $(8)$ & 18 & $(1)$ & 382 & $(4)$ \\
Environment & 78 & $(2)$ & 123 & $(4)$ & 104 & $(4)$ & 305 & $(3)$ \\
Defense & 98 & $(3)$ & 30 & $(1)$ & 44 & $(2)$ & 172 & $(2)$ \\
& & & & & & & & \\
Total & 3,659 & $(100)$ & 3,453 & $(100)$ & 2,827 & $(100)$ & 9,939 & $(100)$
\end{tabular}

Note: The values represent the frequency of the campaign agenda-related key words in Bush and Gore's Web sites. The values in the parentheses show the percentage of the agenda values within each time period.

Time $1=20$ to 28 September 2000

Time $2=12$ to 20 October 2000

Time $3=27$ October to 6 November 2000

3,415 hits out of 81,065 words. Gore's Web site had more text and more agenda-relevant keywords than did Bush's Web site.

As Table 1 reveals, "health care" had the most issue salience in each time period, but the coverage proportion of "health care" decreased over time. On the other hand, the agenda proportion of "Social Security" and "economy" increased over time. In particular, "Social Security" dramatically changed rank order from seventh at Time 1 to second at Time 2 and Time 3. Generally, "crime," "environment," and "defense" received less emphasis than other issues in the 2000 presidential campaign periods.

National Newspapers' Campaign Agenda. The greatest issue coverage in national newspapers, as shown in Table 2, was given to "health care" $^{\prime \prime}(1,123$.issue hits out of 6,923 or $16 \%$ of the total hits), followed by "education" (1,117 hits, 16\%), "economy" (879 hits, 13\%), and "budget handling" (794 hits, 12\%).

Like the "health care" issue on the Web sites, national newspapers reduced the coverage of "health care" over time, although the issue was the most salient overall. As with candidate Web sites, the proportion of "Social Security" emphasis in national newspaper coverage increased over time ( $3 \%$ of the total hits at Time 1 to $12 \%$ at Time 3 ). In contrast with the "economy" issue in candidate Web sites, newspaper coverage of 
TABLE 2

Campaign News Agenda in National Newspapers

\begin{tabular}{|c|c|c|c|c|c|c|c|c|}
\hline & & & ational & ewspa & & & & \\
\hline & & ne 1 & & e 2 & & ne 3 & & \\
\hline & $F$ & $\%$ & $F$ & $\%$ & $F$ & $\%$ & $F$ & $\%$ \\
\hline Energy Policy & 491 & $(21)$ & 28 & (1) & 64 & (2) & 583 & (8) \\
\hline Economy & 442 & (19) & 310 & (16) & 221 & (8) & 879 & (13) \\
\hline Health Care & 399 & (17) & 321 & (16) & 403 & (15) & 1,123 & (16) \\
\hline Education & 257 & (11) & 190 & (10) & 670 & (25) & 1,117 & (16) \\
\hline Crime & 173 & $(8)$ & 151 & $(8)$ & 148 & (6) & 472 & (7) \\
\hline Budget Handling & 148 & (6) & 327 & (17) & 319 & (12) & 794 & (12) \\
\hline Defense & 147 & (6) & 69 & (4) & 71 & (3) & 287 & (4) \\
\hline Taxes & 130 & (6) & 256 & (13) & 266 & (10) & 652 & (9) \\
\hline Social Security & 70 & (3) & 225 & (11) & 303 & (12) & 598 & (9) \\
\hline Environment & 42 & $(2)$ & 107 & (5) & 175 & (7) & 324 & (5) \\
\hline Total & 2,299 & $(100)$ & 1,984 & $(100)$ & 2,640 & $(100)$ & 6,923 & $(100)$ \\
\hline
\end{tabular}

Note: The values represent the frequency of the campaign agenda-related key words in the two national newspapers. The values in the parentheses show the percentage of the agenda values within each time period.

Time $1=20$ to 28 September 2000

Time $2=12$ to 20 October 2000

Time $3=27$ October to 6 November 2000

"economy" dramatically decreased over time ( $19 \%$ of the total hits at Time 1 to $8 \%$ at Time 3). The "crime," "environment," and "defense" issues were the least emphasized in the national newspapers.

Television's Campaign Agenda. As shown in Table 3, television networks gave the greatest issue coverage to "energy policy" $(1,170$ seconds out of 9,120 , or $19 \%$ of the total campaign newscasts), followed by "economy" (1,551 seconds, $17 \%)$ and "budget handling" (1,448 seconds, $16 \%$ ).

The television networks, however, also showed different issue priorities over time. For example, the "energy policy" issue was the predominant issue at Time 1, "education" was the most salient issue at Time 2, and "Social Security" was most emphasized at Time 3 (respectively, $45 \%, 38 \%, 35 \%$ ).

"Defense," "crime," and "environment" were the least-covered campaign issues by the three networks. The number of issues covered via television was increasingly diversified as Election Day drew near. Only the "economy" and "education" were covered by the networks in all three time periods chosen in this study. The coverage proportion of the "economy" issue declined over time, while the "budget handling," "taxes," "Social Security," and "environment" increased over time. 
TABLE 3

Campaign News Agenda in Television

Television

\begin{tabular}{|c|c|c|c|c|c|c|c|c|}
\hline & \multicolumn{6}{|c|}{ Television } & \multirow{2}{*}{\multicolumn{2}{|c|}{ Total }} \\
\hline & \multicolumn{2}{|c|}{ Time 1} & \multicolumn{2}{|c|}{ Time 2} & \multicolumn{2}{|c|}{ Time 3} & & \\
\hline & $F$ & $\%$ & $F$ & $\%$ & $F$ & $\%$ & $F$ & $\%$ \\
\hline Energy Policy & 1,770 & (45) & 0 & (0) & 0 & $(0)$ & 1,770 & (19) \\
\hline Health Care & 904 & (23) & 0 & $(0)$ & 250 & (9) & 1,154 & (13) \\
\hline Economy & 884 & (23) & 420 & (19) & 247 & (9) & 1,551 & $(17)$ \\
\hline Education & 310 & $(8)$ & 893 & $(38)$ & 148 & (5) & 1,351 & (15) \\
\hline Defense & 30 & (1) & 0 & $(0)$ & 0 & $(0)$ & 30 & $(0)$ \\
\hline Crime & 0 & $(0)$ & 152 & $(7)$ & 36 & (1) & 188 & (2) \\
\hline Budget Handling & 0 & $(0)$ & 572 & $(24)$ & 876 & (31) & 1,448 & (16) \\
\hline Taxes & 0 & $(0)$ & 0 & (0) & 282 & $(10)$ & 282 & (3) \\
\hline Social Security & 0 & $(0)$ & 318 & $(14)$ & 1,006 & (35) & 1,324 & (15) \\
\hline Environment & 0 & $(0)$ & 0 & $(0)$ & 22 & (1) & 22 & $(0)$ \\
\hline Total & 3,898 & $(100)$ & 2,355 & $(100)$ & 2,867 & (100) & 9,120 & $(100)$ \\
\hline
\end{tabular}

Note: The values represent the time (sec.) of the campaign issue agenda aired through the three televisions. The values in the parentheses show the percentage of the agenda values within each time period.

Time $1=20$ to 28 September 2000

Time $2=12$ to 20 October 2000

Time $3=27$ October to 6 November 2000

Intermedia Agenda Setting: Web Site vs. Traditional News Media. RQ1 examined the intermedia agenda-setting impact of candidate Web sites on the traditional news media. To answer this question, the study focused on the relationship between each candidate's Web site and the traditional news media (national newspapers and television), and between the Web sites as news media and the traditional news media.

Each Candidate Web Site vs. Traditional News Media. Each candidate Web site was compared to the traditional news media to assess its impact in setting the media's 2000 campaign issue agendas. Using Spearman correlations and Rozelle-Campbell baseline statistics, as shown in Figure 1 , the correlation coefficients between Gore's Web site at Time 1 or Time 2 and the traditional news media reached statistical significance with national newspaper coverage at Time $2(+.58)$ and at Time $3(+.73)$. However, since the cross-lagged correlation between national newspaper coverage at Time 2 and Gore's Web site at Time 3 were statistically significant, both Gore's Web site and national newspaper coverage at Time 2 and Time 3 were reciprocal. In addition, the Spearman $r$ between national newspaper coverage at Time 2 and Gore's Web site at Time 3 revealed greater statistical significance than the cross-lagged correlation between Gore's Web site at Time 2 and national newspapers at Time 3. Thus, the impact of Gore's Web site at Time 2 on national newspaper 
coverage at Time 3 was not as clear as the relationship between Gore's Web site at Time 1 and national newspaper coverage at Time 2.

Further, because the correlation coefficient between Gore's Web site at Time 1 and the newspaper agenda at Time $2(+.58)$ exceeded the baseline $(+.20)$, and the coefficient between Gore's Web site at Time 1 and newspapers at Time $3(+.48)$ were greater than the baseline of +.28 , Gore's Web site at Time 1 showed a significant intermedia agenda-setting impact on national newspapers at Time 1 and Time 3.

The correlations between Gore's Web site and television coverage also revealed that Gore's Web site at Time 2 had a statistically significant impact on the television agenda at Time $3(+.89)$. The Rozelle-Campbell baseline between Gore's Web site and the television agenda further supported the relationship between Gore's Web site at Time 2 and the television agenda at Time 3 . In addition, the baseline between Gore's Web site at Time 1 and television at Time $3(+.33)$ indicates that since the correlation coefficient of +.39 surpassed the baseline, there was a significant relationship between Gore's Web site at Time 1 and television coverage at Time 3.

The cross-lagged correlations between Bush's Web site and the traditional news media, as shown in Figure 2, revealed that Bush's Web site at Time 2 had significant intermedia agenda-setting impact on the national newspaper and television news at Time 3 (respectively, +.66 , +.85 ). The Rozelle-Campbell baseline not only supported the relationship between Bush's Web site at Time 2 and the national newspaper and television at Time 3, but also revealed that Bush's Web site at Time 1 had a statistically significant effect on national newspaper and television agendas at Time 2 and Time 3 , since the correlation coefficients (respectively, $+.53,+.47,+.41,+.44$ ) exceeded the baseline (respectively, +.27 , $+.23,+.13,+.33)$.

Overall, Gore's Web site had some significant intermedia agendasetting impact in the following relationships: Gore's Web site at Time 1 and national newspaper at Time 2 and Time 3, Gore's Web site at Time 1 and television at Time 3, and Gore's Web site at Time 2 and television at Time 3. However, there were no significant intermedia agenda-setting impacts between Gore's Web site at Time 1 and the television at Time 2, and between Gore's Web site at Time 2 and national newspapers at Time 3. Therefore, Bush's Web site showed statistically more significant impact on the traditional news media across all the time periods that Gore's Web site. That is, the results suggest that Bush's Web site had greater intermedia agenda-setting impact on the traditional news media than Gore's Web site.

Web Site as New Media vs. Traditional News Media. According to the cross-lagged correlations between the Web sites and television across time, as shown in Figure 3, the Web sites at Time 2 had a significant relationship with the television and national newspaper coverage at Time 3 (respectively, Spearman $r=+.88,+.67$ ). However, since there was a significant relationship between the national newspapers at Time 2 and candidate Web sites at Time $3(+.76)$, the media agendas between the Web sites and the national newspapers at Time 2 and Time 3 were found to be reciprocal. Thus, the cross-lagged correla- 
FIGURE 1

Results of Cross-Lagged Comparison between Gore's Web Site and the Traditional Media Agendas

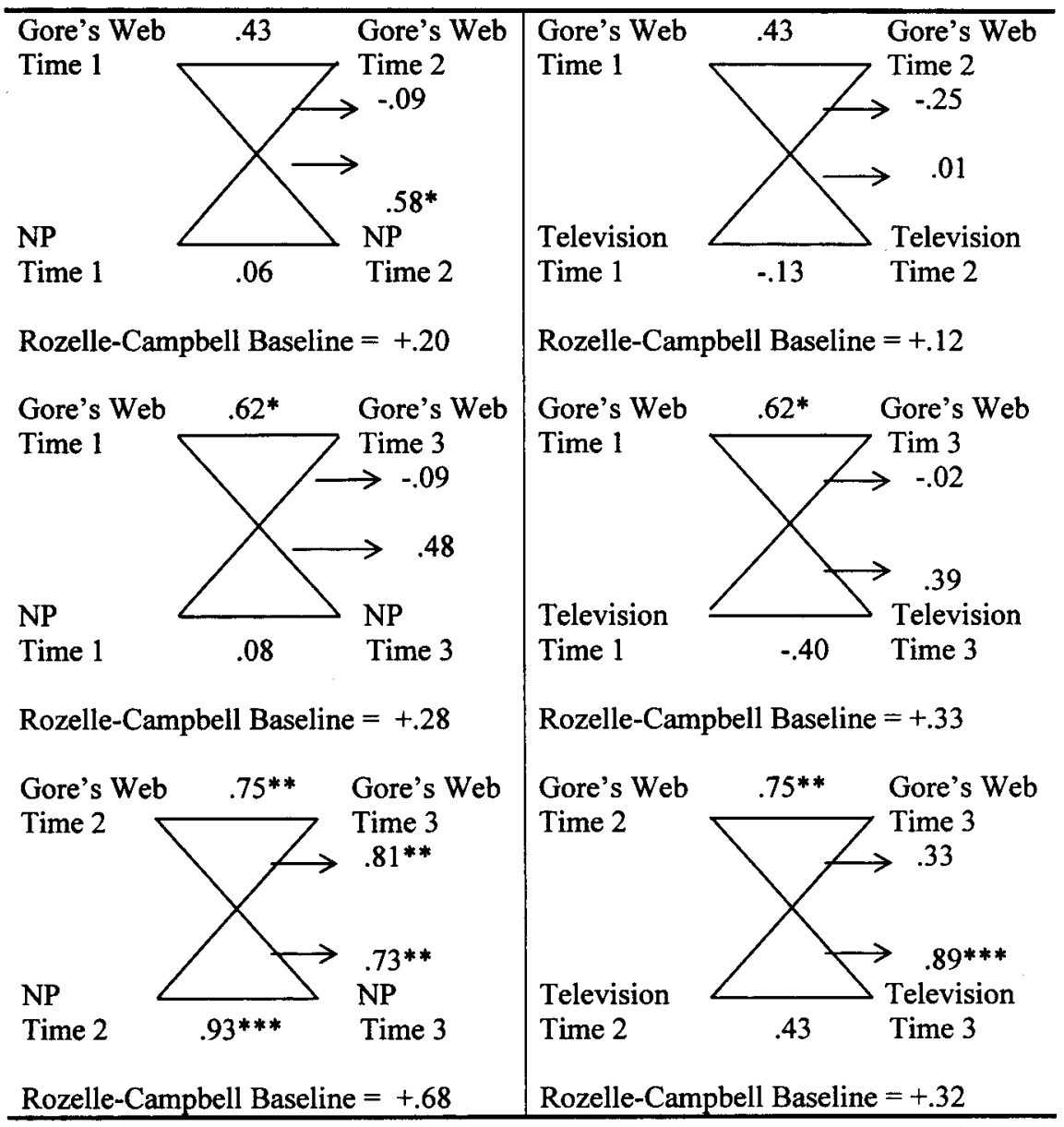

Time $1=20$ to 28 September 2000

Time $2=12$ to 20 October 2000

Time $3=27$ October to 6 November 2000

$\mathrm{NP}=$ national newspaper

${ }^{*} p<.05 ;{ }^{* *} p<.01 ;{ }^{* * *} p<.001$.

tions only revealed the impact of Web site at Time 2 on the television campaign coverage at Time 3 .

However, as shown in Figure 3, use of the Rozelle-Campbell baseline statistic to determine significance further revealed that the presidential candidates' Web sites had some intermedia agenda-setting impact on the traditional news media coverage. According to Figure 3, 


\section{FIGURE 2}

Results of Cross-Lagged Comparison between Bush's Web Site and the Traditional Media Agendas

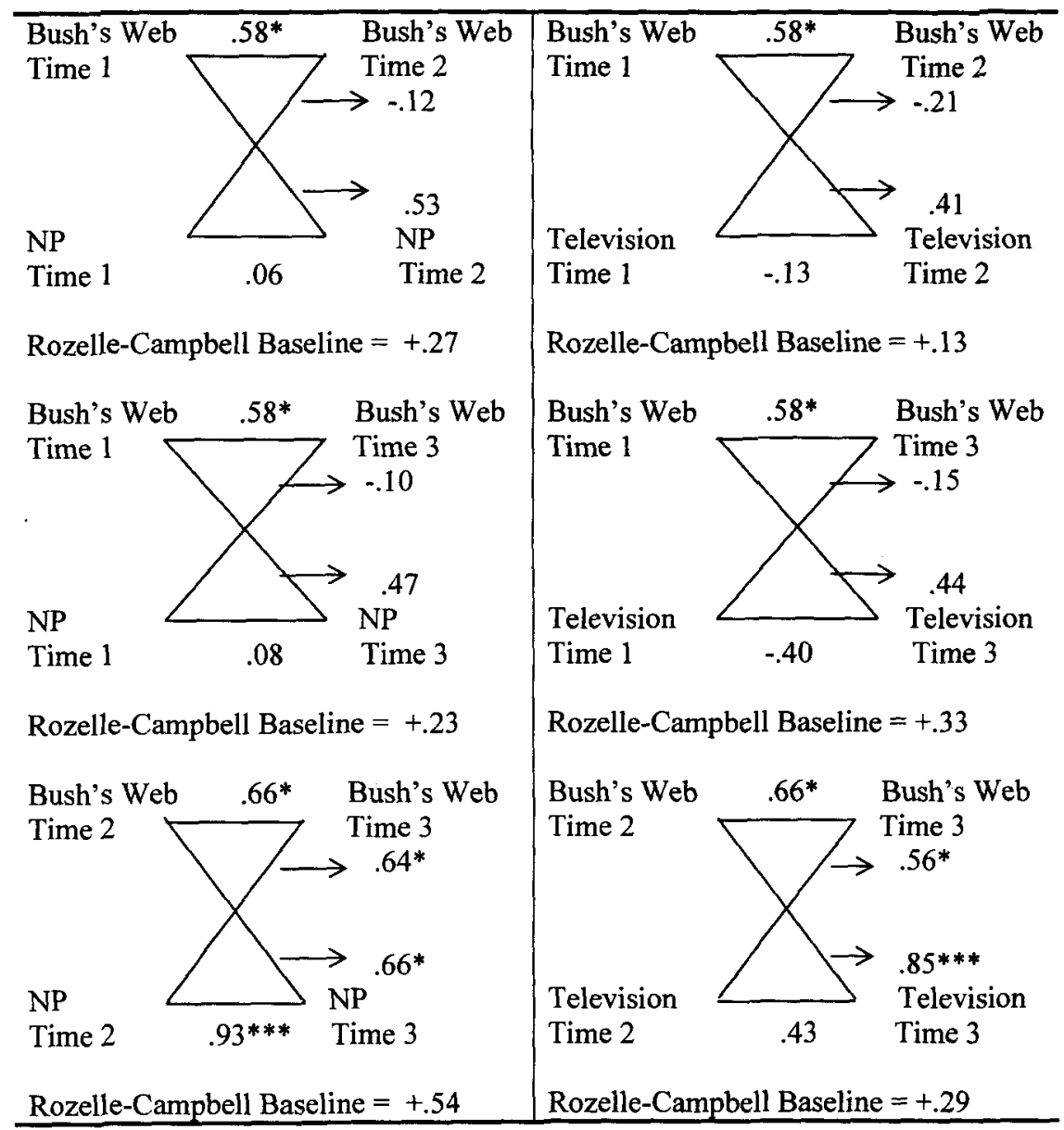

Time $1=20$ to 28 September 2000

Time $2=12$ to 20 October 2000

Time $3=27$ October to 6 November 2000

$\mathrm{NP}=$ national newspaper

${ }^{*} p<.05 ;{ }^{* *} p<.01 ;{ }^{* *} p<.001$.

since the Spearman correlation coefficient between the Web site agendas at Time 1 and the television agenda at Time $3(+.35)$, and the coefficients between the Web site at Time 1 and the national newspaper agenda at Time 2 and Time 3 (respectively, $+.53,+.39$ ) exceeded the baseline statistic value (respectively, $+.32,+21,+.27$ ), additional Web site impact on the traditional media was substantiated. 


\section{FIGURE 3}

Results of Cross-Lagged Correlation Coefficients and the Rozelle-Campbell Baseline between Web Site and Traditional News Media across Time

\begin{tabular}{|l|l|ll|}
\hline Website \\
Time 1 \\
Television \\
Time 1
\end{tabular}

Time $1=20$ to 28 September 2000

Time $2=12$ to 20 October 2000

Time $3=27$ October to 6 November 2000

NP = national newspaper

${ }^{*} p<.05 ;{ }^{* *} p<.01 ;{ }^{* * *} p<.001$.

The data analyses described above using Spearman correlations and Rozelle-Campbell baseline statistics were further analyzed using partial correlations. Each entry $A$ in Table 4 shows the previously reported outcome of the cross-lagged correlations between independent and dependent variable. The earlier values of the dependent variable as a predictor of the dependent variable at Time 2 were considered at entry 


\section{TABLE 4 \\ Additional Analysis of Correlations between Web Site and Traditional News Media across Time}

I. $\quad$ Website $\langle$ Time 1$\rangle \rightarrow$ Television $\langle$ Time 2$\rangle$

A. Cross-lag correlation (zero-order): $\quad+.16$

B. First-order partial correlation controlling for the dependent variable, $\quad+.27$ television news, at Time 1:

C. First-order partial correlation controlling for the other major influence $\quad+.09$ identified in this study, national newspaper's news, at Time 1:

D. Second-order partial correlation controlling for both television and $\quad+.15$ national newspaper's news at Time 1:

II. Website $<$ Time $1>\rightarrow$ NP $<$ Time 2>

A. Cross-lag correlation (zero-order): $\quad+.53$

B. First-order partial correlation controlling for the dependent variable, $\quad+.61$ national newspaper's news, at Time 1:

C. First-order partial correlation controlling for the other major influence $\quad+.71$ identified in this study, television news, at Time 1:

D. Second-order partial correlation controlling for both national newspaper $\quad+.68$ and television news at Time 1 :

III. Website $<$ Time $1>\rightarrow$ Television $<$ Time $3>$

A. Cross-lag correlation (zero-order):

B. First-order partial correlation controlling for the dependent variable, $\quad+.72$ television news, at Time 1:

C. First-order partial correlation controlling for the other major influence $\quad+.63$ identified in this study, national newspaper's news, at Time 1:

D. Second-order partial correlation controlling for both television and $\quad+.71$

IV. Website $<$ Time $1>\rightarrow$ NP $<$ Time $3>$

A. Cross-lag correlation (zero-order): $\quad+.39$

B. First-order partial correlation controlling for the dependent variable, $\quad+.43$ national newspaper's news, at Time 1:

C. First-order partial correlation controlling for the other major influence $\quad+.47$ identified in this study, television news, at Time 1:

D. Second-order partial correlation controlling for both national newspaper $\quad+.45$ and television news at Time 1:

V. Website $<$ Time $2>\rightarrow$ Television $<$ Time 3>

A. Cross-lag correlation (zero-order): $\quad+.88$

B. First-order partial correlation controlling for the dependent variable, $\quad+.88$ television news, at Time 2:

C. First-order partial correlation controlling for the other major influence $\quad+.65$ identified in this study, national newspaper's news, at Time 2:

D. Second-order partial correlation controlling for both television and $\quad+.69$ newspaper's news at Time 2:

VI. Website $\langle$ Time $2>\rightarrow$ NP $<$ Time $3>$

A. Cross-lag correlation (zero-order): $\quad+.67$

B. First-order partial correlation controlling for the dependent variable, $\quad \mathbf{\quad . 2 2}$ national newspaper news, at Time 2:

C. First-order partial correlation controlling for the other major influence $\quad+.65$ identified in this study, television news, at Time 2:

D. Second-order partial correlation controlling for both national newspaper $\quad-.22$ and television news at Time 2:

Note: The values represent the zero-order and partial correlation coefficients between two variables and between two variables after controlling other variable(s).

Time $1=20$ to 28 September 2000

Time $2=12$ to 20 October 2000

Time $3=27$ October to 6 November 2000

$\mathrm{NP}=$ national newspaper. 
Bs in Table 4. Entry Bs indicate how much the predictive power of the independent variables at Time 1 will be diminished by controlling for the dependent variables at Time 1 . In entry Cs, the relationship between independent and dependent variable is examined with the impact of another major predictor removed. In entry Ds, the effects of both the dependent variable at Time 1 and the other predictor are controlled simultaneously to see the impact of the independent variable on the dependent.

Entry B, C, and D in II, III, IV, and V, as shown in Table 4, revealed that the first-order and second-order partials were even larger than the original zero-order correlation coefficients. Even with the introduction of additional controls, there were still significant Web site effects in the following: Web site at Time 1 and national newspaper coverage at Time 2 and Time 3, Web site at Time 1 and television coverage at Time 3 , and Web site at Time 2 and television coverage at Time 3 . Thus, the results of partial correlations were identical with the results analyzed by Spearman correlations and Rozell-Campbell baseline statistics.

Agenda Setting of Internet Campaigning. This study also examined the impact of the Web sites on the public's agenda in assessing how they influenced public opinion. The following research question explored the agenda-setting function of candidate Web sites: How do the presidential candidates' Web sites influence the public agenda?

First, to see whether media agendas significantly set the public agenda, each media agenda at Time 1 and Time 2 were cross-lagged with public agenda at Time 2 and Time 3 . Based on the Spearman correlations, the present research investigated the size of agenda-setting impact of news media on the public. Figure 4 indicates the presidential candidates' Web sites had some significant agenda-setting function on the public in the following time periods: the Web site agenda at Time 1 on the public's agenda at Time 2(+.60); Web site at Time 2 on the public's agenda at Time $3(+.76)$. In particular, the Web sites' agenda-setting function was greater than the national newspapers and television in both time periods chosen in this study.

As shown in Figure 4, the television agenda did not have any agenda-setting impact on the public's agenda. But newspaper coverage at Time 2 showed a significant agenda-setting impact on the public (+.67). Generally, the correlation coefficients between each medium and the public were higher in the last time period of the election campaign than in the period.

To see the path of media impact on the public's agenda, the present study regressed the public's agenda on three news media (Web sites, national newspaper, and television) at each time period. To begin with, Model \#1 in Figure 5 revealed that candidate Web site at Time 1 was significantly related to the public's agenda at Time $2(+.85)$. However, there was no significant relationship between the television and newspaper coverage at Time 1 and the public agenda at Time 2 .

Model \#2 in Figure 5 also revealed that Web sites exerted significant direct impact on the public's agenda at Time $3(+.83)$. However, the coefficient for national newspaper at Time 1 and Time 2 and television coverage at Time 1 and Time 2 were not statistically significant. On the 


\section{FIGURE 4}

Agenda-Setting Function of News Media on Public Opinion across Time

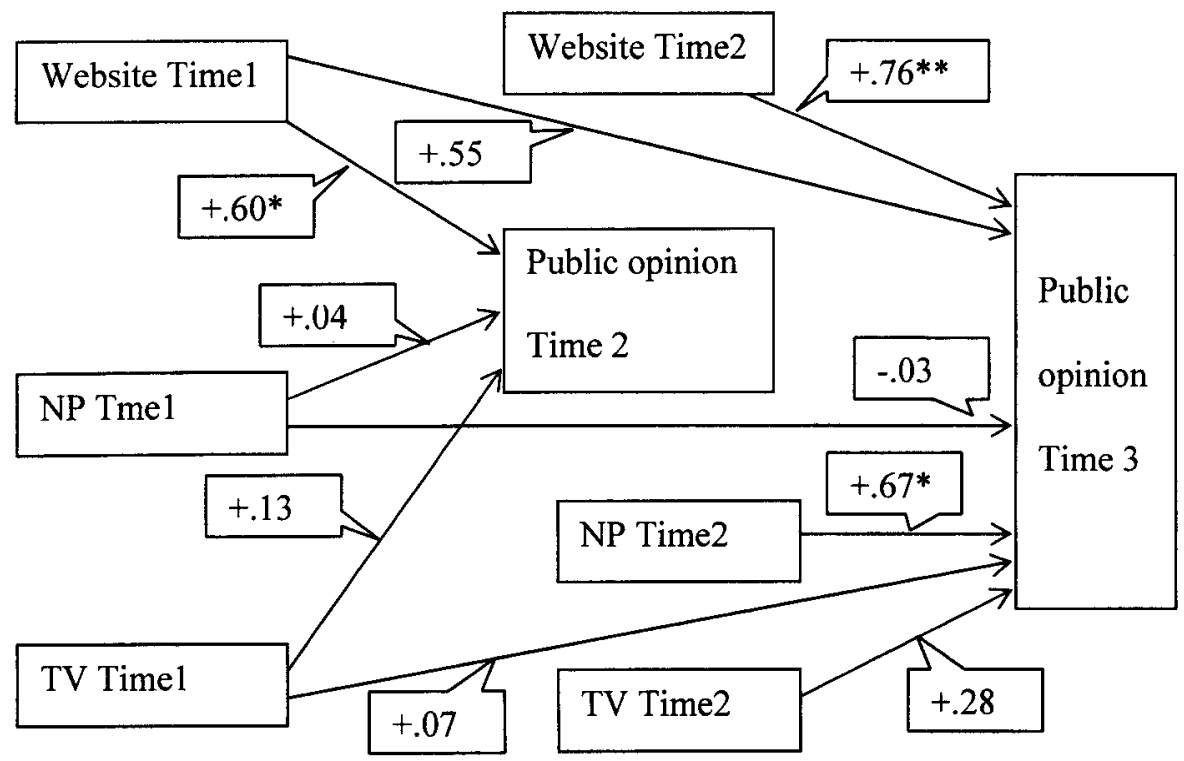

Time $1=20$ to 28 September 2000

Time $2=12$ to 20 October 2000

Time $3=27$ October to 6 November 2000

$\mathrm{NP}=$ national newspaper

${ }^{*} p<.05 ;{ }^{*} p<.01$.

other hand, the analysis also suggests that multicollinearity exists when the television agenda at Time 2 was regressed with television, Web site, and national newspaper agendas at Time 1 . The tolerance statistic and variance inflation factor (VIF) in regression analysis were used to determine how much the independent variables are linearly related to one another.

Overall, the two path models shown in Figure 5 indicated that candidate Web site agendas in the initial campaign phase had some significant direct agenda-setting impact on the public's agenda, and the agenda-setting impact persisted throughout the 2000 presidential campaign period.

\section{Discussion}

Since the 1996 presidential election campaign, political uses of the Internet have increased dramatically. Some studies have revealed that the online networks influence the public's exposure to campaign information as well as becoming news sources for the traditional news media. ${ }^{35}$ In this context, this exploratory study sought to understand 


\section{FIGURE 5}

Path Diagram Depicting Agenda-Setting Function of News Media on Public Opinion across Time
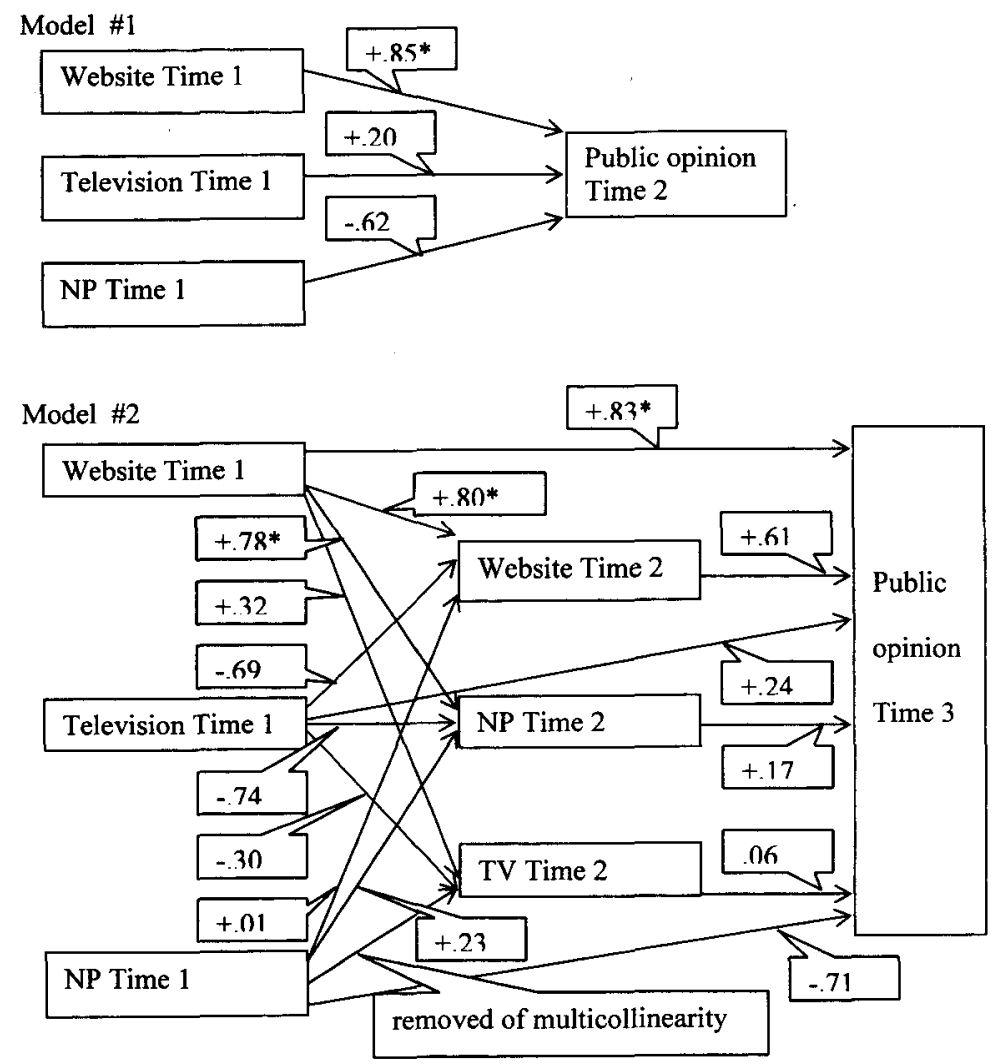

Time $1=20$ to 28 September 2000

Time $2=12$ to 20 October 2000

Time $3=27$ October to 6 November 2000

$\mathrm{NP}=$ national newspaper

${ }^{*} p<.05$.

agenda-setting processes in relation to other media agendas and the public's agenda in this new information age.

Several implications of political candidate Web sites on political dialogue were found. First, Web site campaigning can be used as a useful tool for effective public relations, since the campaign agenda of candidate Web sites became the subsequent agenda of the traditional news media. Second, as Web site agendas are actively involved in the traditional media agenda, candidate Web site agendas are more likely to be associated with the public agenda. Another theoretical implication regarding the agenda-setting function is that online users exposed to candidate Web sites are more likely to be exposed to the campaign 
agendas than traditional media users. Although the exact functional relationships between the Web sites' agenda and the public agenda remain to be specified, there is strong evidence of a convergence of the public's attention to the issues on the Web sites. In addition, the path analysis regarding the Web site impact on the public agenda revealed that candidate Web sites had the only direct agenda-setting impact on the public. This finding might indicate that a political candidate who wants to run a Web site needs to focus on direct Web site strategies to reach online users, as well as provide news releases for the traditional news media. Finally, the agenda-setting function shown in the later phase of the campaign was accomplished in a relatively shorter time compared with that of the initial phase. This might imply that the optimal time frame between media and public for the agenda-setting function is shortened.

Internet-based communication has established powerful new links between politicians and voters and created great impact on the information flow of the traditional news media. Clearly, candidate-controlled Web sites are having some of the same direct effects on news media agendas that have been identified for candidate-controlled political advertising in previous research. Future research might explore the relationship between candidate advertising and candidate Web sites, as well as the interrelationships among all these potential information sources for the public. In particular, the great potential of Internet Web sites as a means of communicating with the electorate is a noteworthy implication. As computer networks are expected to grow dramatically, electronic forms of communication will close the gap between citizens and politicians, and encourage the development of more informed citizens. Thus, individual voters might increase the capacity to identify issues of common interest, so that they would enhance civic participation toward more healthy democracy.

\section{NOTES}

1. David L. Protess and Maxwell McCombs, eds., Agenda Setting: Readings on Media, Public Opinion, and Policymaking (Hillsdale, NJ: Lawrence Erlbaum, 1991).

2. See, for example, Roger W. Cobb, and Charles Elder, "The Politics of Agenda-building: An Alternative Perspective for Modern Democratic Theory," Journal of Politics 33 (1971): 892-915; Marilyn Roberts and Maxwell McCombs, "Agenda Setting and Political Advertising: Origins of the News Agendas," Political Communication 11 (July-September 1994): 249-62; Everett M. Rogers, James W. Dearing, and Dorine Bregman, "The Anatomy of Agenda-Setting Research," Journal of Communication 43 (spring 1993): 68-84.

3. Roberts and McCombs, "Agenda Setting and Political Advertising: Origins of the News Agenda."

4. Kenneth Hacker, Lori Howl, Max Scott, and Robert Steiner, “Uses of Computer-mediated Political Communication in the 1992 Presidential Campaign: A Content Analysis of the Bush, Clinton, \& Perot Computer 
Lists," Communication Research Reports 13 (fall 1996): 138-46; Rita K. Whillock, "Cyber-politics," American Behavioral Scientist 40 (August 1997): 1208-1225.

5. Tora K. Bikson and Constantijn W. A. Panis, "Citizens, Computers, and Connectivity: A Review of Trends," 1999, available at http:// www.rand.org/publications/MR/MR650/mr750.ch2/ch2.html; html; Whillock, "Cyber-politics."

6. Hacker et al., "Uses of Computer-mediated Political Communication in the 1992 Presidential Campaign: A Content Analysis of the Bush, Clinton, \& Perot Computer Lists"; Whillock, "Cyber-politics."

7. Randy Bobbitt, "An Internet Primer for Public Relations," Public Relations Quarterly 40 (fall 1995): 27-32; Anthony Corrado, "Elections in Cyberspace: Prospects and Problems," in Elections in Cyberspace: Toward a New Era in American Politics, ed. Anthony Corrado and Charles M. Firestone (Washington, DC: The Aspen Institute, 1996), 1-31: John C. Tedesco, Jerry L. Miller, and Julia A. Spiker, "Presidential Campaigning on the Information Superhighway: An Exploration of Content and Form," in The Electronic Election, ed. Lynda Lee Kaid and Dianne G. Boystrom (Mahwah, NJ: Lawrence Erlbaum, 1999), 61-63.

8. Anthony Corrado, "Elections in Cyberspace: Prospects and Problems"; Hacker et al., "Uses of Computer-mediated Political Communication in the 1992 Presidential Campaign: A Content Analysis of the Bush, Clinton, \& Perot Computer Lists"; Whillock, "Cyber-politics."

9. Whillock, "Cyber-politics."

10. Robert Klotz, "Positive Spin: Senate Campaigning on the Web," Political Science \& Politics 30 (1997): 482-86.

11. Sam Vincent Meddis, "Political Action on the Web Offers a Boost to Presidential Campaigns," available at http://www.usatoday.com/ life/cyber/ccarch/cc0401.htm.

12. Richard Davis, The Web of Politics (New York: Oxford University Press, 1999); Colin Sparks, "The Internet and the Global Public Sphere," in Mediated Politics: Communication in the Future of Democracy, ed. W. Lance Bennett and Robert. M. Entman (Cambridge: Cambridge University Press, 2001), 75-98.

13. Whillock, "Cyber-politics."

14. Phil Noble, "Net the Vote," Campaigns \& Elections, July 1996, 2728.

15. See, for example, Erik P. Bucy, Paul D'Angelo, and John E. Newhagen, "The Engaged Electorate: New Media Use as Political Participation," in The Electronic Election: Perspectives on the 1996 Campaign Communication, ed. Lynda Lee Kaid and Dianne G. Bystrom (Mahwah, NJ: Lawrence Erlbaum, 1999), 335-47; Corrado, "Elections in Cyberspace: Prospects and Problems"; Michael Magolis and David Resnick, "Campaigning on the Internet: Parties and Candidates on the World Wide Web in the 1996 Primary Season," Press/Politics 2 (winter 1997):59-78; Tedesco, Miller, and Spiker, "Presidential Campaigning on the Information Superhighway: An Exploration of Content and Form."

16. Maxwell McCombs and Donald L. Shaw, "The Agenda-setting Function of Mass Media," Public Opinion Quarterly 36 (summer 1972): 176-87. 
17. Lee B. Becker, Maxwell E. McCombs, and Jack M. McLeod, "The Development of Political Cognitions," in Political Communication, ed. Steven H. Chaffee (Beverly Hills, CA: Sage, 1975), 21-63; James W. Dearing and Everett M. Rogers, Agenda-Setting (Beverly Hills, CA: Sage, 1996), 1-2.

18. Gladys E. Lang and Kurt Lang, "Watergate: An Exploration of the Agenda-Building Process," in Agenda Setting: Readings on Media, Public Opinion, and Policymaking, ed. Protess and McCombs, 278.

19. Maxwell E. McCombs, "Newspapers versus Television: Mass Communication Effects across Time," in The Emergence of American Political Issues: The Agenda-setting Function of the Press, ed. Donald L. Shaw and Maxwell E. McCombs (St. Paul: West Publishing Co., 1977), 89-105. Wayne Wanta examines effects of different media on agenda setting in The Public and the National Agenda: How People Learn about Important Issues (Mahwah, NJ: Lawrence Erlbaum, 1997), 62-78.

20. Maxwell E. McCombs and Donald L. Shaw, "Agenda-Setting and the Political Process," in The Emergence of American Political Issues: The Agenda-setting Function of the Press, ed. Donald L. Shaw and Maxwell E. McCombs (St. Paul: West Publishing Co., 1977), 155-56.

21. Walter Cronkite, "Reporting Presidential Campaigns: A Journalist's View," in The Politics of News: The News of Politics, ed. Doris Graber, Denis McQuail, and Pippa Norris (Washington, DC: Congressional Quarterly Press, 1998), 57-69.

22. Rogers, Dearing, and Bregman, "The Anatomy of Agenda-Setting Research."

23. See, for example, Tony Atwater, Frederick Fico, and Gary Pizante, "Reporting on the State Legislature: A Case of Inter-media Agenda Setting," Newspaper Research Journal 8 (2, 1987): 52-61; Stephen D. Reese and Lucig H. Danielian, "Intermedia Influence and the Drug Issue: Converging on Cocaine," in Agenda Setting: Readings on Media, Public Opinion, and Policymaking, ed. Protess and McCombs, 237-49; Oscar Gandy, "Beyond Agenda Setting," in Agenda Setting: Readings on Media, Public Opinion, and Policymaking, ed. Protess and McCombs, 263-75.

24. Atwater, Fico, and Pizante, "Reporting on the State Legislature: A Case of Inter-media Agenda Setting"; Reese and Danielian, "Intermedia Influence and the Drug Issue: Converging on Cocaine." Reese and Danielian's study, focusing on news coverage of cocaine issues, found that the print media, especially the New York Times, set the agenda for the television networks. Atwater, Fico, and Pizante also support the agendasetting function of newspapers on the broadcast agenda for statehouse stories.

25. Roberts and McCombs, "Agenda Setting and Political Advertising: Origins of the News Agenda."

26. Thomas Boyle, "Intermedia Agenda Setting in the 1996 Presidential Election," Journalism \& Mass Communication Quarterly 78 (spring 2001): 26-44.

27. Kathleen Hall Jamieson and Karlyn Khors Campbell, The Interplay of Influence: News, Advertising, Politics, and the Mass Media (Belmont, CA: Wadsworth, 1997); Herbert J. Gans, Deciding What's News: A Study of CBS Evening News, NBC Nightly News, Newsweek, and Time (New York: Pan- 
theon Books, 1979); Cronkite, "Reporting Presidential Campaigns: A Journalist's View."

28. See, for example, Don Middleberg, Winning PR in the Wired World, (New York, NY: McGraw-Hill, 2001); Whillock, "Cyber-politics."

29. Lynda Lee Kaid and Keith R. Sanders, "Survey of Political Communication Theory and Research," in Political Communication Yearbook, ed. Lynda Lee Kaid, Keith R. Sanders, and D. Nimmo (Carbondale, IL: Southern Illinois University Press, 1984), 283-308.

30 . The chosen ten issues and issue related words: Healthcare - health care, drug, prescription, medicine, doctor, medicare, medicaid, medication, pharmacy, H.M.O (HMO[s]), insurance, patient, disease, CHIP; Social Security - social security, benefits, beneficiary, retirement, welfare; Energy policy - OPEC, oil, gas, petroleum, gasoline, energy, fuel, crude; Education - education, school, student, enrollment, tuition, college; Economy - business, economy, industry, market, invest, company, job, interest rates, $\mathrm{R} \& \mathrm{D}$ (research and development); Taxes - tax, marriage penalty; Environment - environment, pollute, air; National Defense - security, defense, military, army; Handling budget - budget, spending, fund, surplus, debt, deficit, solvent; Crime - crime, criminal, violence, gun, police, law enforcement.

31. Lynda Lee Kaid and Anne J. Wadsworth, "Content Analysis," in Measurement of communication behavior, ed. Phillip Emmert and Larry L. Barker (NY: Longman, 1989), 197-217.

32. Roberts and McCombs, "Agenda Setting and Political Advertising: Origins of the News Agenda," 256.

33. Leonard Tipton, Roger D. Haney and John R. Baseheart, "Media Agenda-setting in City and State Election Campaigns," Journalism Quarterly (spring 1975): 15-22; See, also, Roberts and McCombs, "Agenda Setting and Political Advertising: Origins of the News Agenda." The formula for the baseline statistic proposed by researchers is:

$$
\frac { X _ { 1 } Y _ { 1 } + X _ { 2 } / Y _ { 2 } } { 2 } \longdiv { \frac { ( X _ { 1 } X _ { 2 } ) ^ { 2 } + ( Y _ { 1 } / Y _ { 2 } ) ^ { 2 } } { 2 } }
$$

34. Roberts and McCombs, "Agenda Setting and Political Advertising: Origins of the News Agenda."

35. See, for example, Bikson and Panis, "Citizens, Computers, and Connectivity: A Review of Trends"; Hacker et al., "Uses of Computermediated Political Communication in the 1992 Presidential Campaign: A Content Analysis of the Bush, Clinton, \& Perot Computer Lists"; Noble, "Net the Vote"; Whillock, "Cyber-politics." 